\title{
Prolonged aftereffects of a single foot shock
}

ROBERT J. BLANCHARD, TED E. DIELMAN AND D. CAROLINE BLANCHARD UNIVERSITY OF HAWAII

A time-sampling procedure was used to study the behavior of rats following a single foot shock. The Ss who received a $2 \mathrm{sec}, 1.3 \mathrm{~mA}$ shock crouched more, lay down less, and were initially less active, than nonshocked controls. Crouching differences were greatest during the first 30 min after shock, and declined systematically over a $3 \mathrm{~h}$ period. The results were interpreted as indicating that foot shock produces gross behavioral changes which may affect the dependent variables of experiments involving such shock.

Although electric foot shock is probably the most frequently used noxious stimulus in animal research, little systematic information on the aftereffects of foot shock is available. However, a considerable number of investigators have noted that rats tend to become immobile (Davits, 1954) or to assume a stereotyped "crouching" or "freezing" posture (e.g., Krieckhaus, 1965) in situations involving shock. If such reactions do accompany shock, they may possibly enhance or interfere with the behaviors measured in experiments involving shock. The present experiment therefore attempted to determine if a single foot shock produces relatively long lasting modifications of the rat's behavior.

\section{Subjects}

The Ss were 24 naive female albino rats, from 90-110 days of age from the colony maintained by the University of Hawaii psychology department.

\section{Apparatus}

The four shock boxes were constructed of black Plexiglas, with one side of clear Plexiglas to permit observation. Each box was divided by a black Plexiglas panel into two, $10 \times 10 \times 12$ in. chambers. The flooring consisted of 5/32 in. copper bars with a $3 / 4$ in. spacing between bars. The boxes were located in a sound attenuating room with their clear sides facing a one-way vision mirror. This arrangement enabled the $E$ to rate eight Ss simultaneously without being seen or heard by the Ss. Grason-Stadler Model E1064 GS shock sources were used to deliver shock to the grids.

\section{Procedure}

The time-sampling technique has been more fully described elsewhere (Bolles, 1965). The present study involved the rating of each $S$ at $30 \mathrm{sec}$ intervals for $3 \mathrm{~h}$ following shock. The rating categories used were: Active, Grooming, Lying, Standing, and Crouching. The first three of these categories were similar to those used by Bolles. The latter two categories were determined on the basis of a pilot investigation. These were: Standing-all S's limbs are extended and support S's weight; and, Crouching-the S's weight is supported by its hindlimbs, which are contracted with forelimbs extended. The S's belly does not support S's weight.

Following a $10 \mathrm{~min}$ habituation period in the boxes, half the Ss received a $1.3 \mathrm{~mA}$ shock of 2 sec duration while the remaining $\mathrm{Ss}$ received no shock. Raters were not present during shock delivery, and they were not informed of the Ss' condition.

\section{Results}

Figure 1 presents the proportions of each response for the two groups as a function of time following shock. During the first postshock hour, the control Ss groomed, stood, and were active a greater proportion of time than were the shocked Ss. However, the control $\mathrm{Ss}^{\circ}$ grooming, standing, and activity rates declined over the remaining $2 \mathrm{~h}$ of rating, while grooming, standing, and activity slightly increased for the shocked group. Both groups displayed an initial low tendency to lie, but the control group displayed a greater increase in lying than the shocked group. The crouching category provided the most consistent differentiation of the groups. Shocked Ss made $74.0 \%$ crouching responses in the first $30 \mathrm{~min}$ following shock, compared to $29.9 \%$ for the control group. The proportion of crouching responses declined gradually during the $3 \mathrm{~h}$ test session. Shocked Ss crouched significantly more than nonshocked Ss throughout the test session $(t=4.27, d f=22, p<.001)$.

\section{Discussion}

The results of the present study indicate that a single foot shock may suppress activity in the albino rat. However, the tendency of the shocked Ss to lie down much less indicates that the suppressive effects of

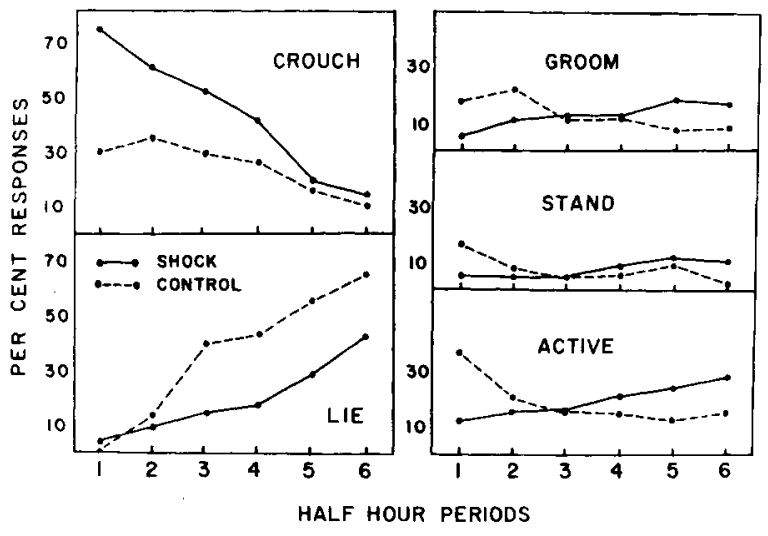

Fig. 1. The proportion of responses in each behavior category during six, $1 / 2 \mathrm{~h}$ periods following a single shock, for rats receiving a $1.3 \mathrm{~mA}$ shock or no shock. 
foot shock are not limited to mobility responses. Thus, rather than increasing immobility per se, foot shock apparently enhances the tendency of the rat to make a specific crouching response.

Konorski (1967) has described a "passive fear reflex" common among small animals who are the subjects of predation. Postshock crouching may be such an unconditioned reflex. It is also conceivable that crouching is under stimulus control, even after the first shock. Finally, crouching may be an initially unconditioned reaction which gradually becomes conditioned to the apparatus cues.

The present experiment does not indicate which of these interpretations is correct. However, the finding that rats tend to crouch for several hours after shock indicates that such crouching may influence the behaviors observed in any study involving massed shocks. If crouching is rapidly conditioned to the cues of the shock situation, it may also be a factor in experiments involving distributed shock.

\section{References}

BOLLES, R. C. Effects of deprivation conditions upon the rat's home cage behavior. J. comp. physiol. Psychol., 1965, 60, 244-248.

DAVITS, J. R. Reinforcement of fear at the beginning and at the end of shock. J. comp. physiol. Psychol., 1955, 48, 152-155.

KONORSKI, J. Integrative activity of the brain: An interdisciplinary approach. Chicago and London: The University of Chicago Press, 1967.

KRIECKHAUS, E. E. Decrements in avoidance behavior following mammillothalamic tractotomy in rats and subsequent recovery with D-amphetamine. J. comp. physiol. Psychol, 1965, 60, 31-35. 